\title{
Agricultura orgânica no oeste do Paraná: um estudo sobre o município de Marechal
}

\section{Cândido Rondon}

\author{
Organic agriculture in west Paraná: a study on the municipality of Marechal Cândido Rondon \\ Agricultura orgánica en Paraná occidental: un estudio sobre el municipio de Marechal Cândido
}

\section{Rondon}

Recebido: 20/10/2021 | Revisado: 28/10/2021 | Aceito: 04/11/2021 | Publicado: 07/11/2021

Juscelino Martins Costa Junior ORCID: https://orcid.org/0000-0001-6166-6461

Universidade Estadual do Oeste do Paraná, Brasil E-mail: juscelinojunio_@hotmail.com

Aline Costa Gonzalez

ORCID: https://orcid.org/0000-0001-9672-8562

Universidade Estadual do Oeste do Paraná, Brasil E-mail: alinecg_15@hotmail.com

Ethol Exime

ORCID: https://orcid.org/0000-0002-6962-8088 Universidade Estadual do Oeste do Paraná, Brasil

E-mail: eeetholl@hotmail.com

Mariell Lima Costa

ORCID: https://orcid.org/0000-0002-4292-9673

Universidade Estadual do Oeste do Paraná, Brasil

E-mail: mariell_lima@hotmail.com

Cleoson Moura dos Reis

ORCID: https://orcid.org/0000-0002-8490-6357

Universidade Estadual do Oeste do Paraná, Brasil

E-mail: cleosonmoura@gmail.com

Alvori Ahlert

ORCID: https://orcid.org/0000-0001-9984-6409

Universidade Estadual do Oeste do Paraná, Brasil E-mail: alvoriahlert@hotmail.com

Vinicius Mattia

ORCID: https://orcid.org/0000-0002-3533-9245

Universidade Estadual do Oeste do Paraná, Brasil

E-mail: vinicius_mattia@hotmail.com

\begin{abstract}
Resumo
Este trabalho teve como objetivo caracterizar os agricultores orgânicos certificados no município de Marechal Cândido Rondon - PR. Pesquisa de natureza qualitativa e quantitativa, estruturada analiticamente com dados obtidos do Censo Agropecuário de 2017, do Instituto Brasileiro de Geografia e Estatística (IBGE), e do Cadastro Nacional de Produtores Orgânicos, além de um levantamento bibliográfico sobre a produção, alimentos e certificação orgânica. $\mathrm{O}$ estudo revelou que do universo de 1.934 estabelecimentos agrícolas do município, apenas 47 (2,4\%) utilizam o sistema orgânico de produção, cuja certificação é realizada pela Associação Ecovida de Certificação Participativa, Instituto de Tecnologia do Paraná e Ecocert Brasil Certificadora. Observou-se que 33 estabelecimentos são de agricultores familiares e 14 unidades de produção não familiares, onde a produção articula-se somente em cultivos (35) ou criações (5) e sistemas misto (7), em propriedades que a área varia de cerca de 0,5 a 20 hectares, e a gestão de 35 propriedades são realizadas por homens e 12 estabelecimentos agrícolas por mulheres. O estudo conclui, que apesar da pouca expressividade quantitativa de agricultores orgânicos no município, a produção orgânica representa um caminho para a transição da produção sustentável de alimentos, por incluir agricultores familiares e não familiares.
\end{abstract}

Palavras-chave: Desenvolvimento rural; Meio ambiente; Produção orgânica.

\begin{abstract}
This work aimed to characterize certified organic farmers in the municipality of Marechal Cândido Rondon - PR. Qualitative and quantitative research, analytically structured on data obtained from the 2017 Agricultural Census, the Brazilian Institute of Geography and Statistics (IBGE), and the National Register of Organic Producers, in addition to a bibliographic survey on production, food and organic certification. The study revealed that from the universe of 1,934 agricultural establishments in the municipality, only $47(2.4 \%)$ use the organic production system, whose certification
\end{abstract}


is carried out by the Ecovida Participative Certification Association, Paraná Institute of Technology and Ecocert Brasil Certificadora. It was observed that 33 establishments are owned by family farmers and 14 non-family production units, where production is articulated only in crops (35) or creations (5) and mixed systems (7), in properties whose area varies by approximately from 0.5 to 20 hectares, and 35 properties are managed by men and 12 farms by women. The study concludes that, despite the limited quantitative expression of organic farmers in the municipality, the organic production represents a path towards the transition of sustainable food production, as they include family and nonfamily farmers.

Keywords: Rural development; Environment; Organic production.

\section{Resumen}

Este trabajo tuvo como objetivo caracterizar a los agricultores ecológicos certificados en el municipio de Marechal Cândido Rondon - PR. Investigación de carácter cualitativo y cuantitativo, estructurada analíticamente con datos obtenidos del Censo Agropecuario 2017 del Instituto Brasileño de Geografía y Estadística (IBGE), y del Registro Nacional de Productores Orgánicos, además de un relevamiento bibliográfico sobre producción, alimentación y certificación orgánica. El estudio reveló que, del universo de 1.934 establecimientos agropecuarios del municipio, sólo $47(2,4 \%)$ utilizan el sistema de producción orgánica, certificado por la Associação Ecovida de Certificação Participativa, el Instituto de Tecnologia do Paraná y Ecocert Brasil Certificadora. Se observó que 33 establecimientos son agricultores familiares y 14 unidades de producción no familiar, donde la producción se articula sólo en cultivos (35) o ganadería (5) y sistemas mixtos (7), en propiedades que la superficie varía de alrededor de 0,5 a 20 hectáreas, y la gestión de 35 propiedades son realizadas por hombres y 12 explotaciones por mujeres. El estudio concluye que, a pesar de la poca representatividad cuantitativa de los agricultores ecológicos en el municipio, la production orgánica representa un camino para la transición de la producción alimentaria sostenible, para incluir a los agricultores familiares y no familiares.

Palabras clave: Desarrollo rural; Medio ambiente; Producción ecológica.

\section{Introdução}

A produção orgânica surge como uma contra proposta ao sistema convencional agrícola. Esse modelo produtivo é fruto da necessidade de uma maior responsabilidade ambiental para atender os anseios da sociedade, buscando a preservação e conservação do meio ambiente e da saúde humana, em meio às transformações agrícolas não sustentáveis que aconteceram mais acentuadamente a partir da Revolução Verde ${ }^{1}$.

Segundo o Instituto Brasileiro de Geografia e Estatística (IBGE, 2019) os alimentos agropecuários são considerados orgânicos quando estão livres de insumos artificiais, como adubos químicos e agrotóxicos. Para a produção, o agricultor, seja ele familiar ou não, tem diversas limitações, muitas vezes relacionadas ao seu planejamento agrícola, já que sem a presença dos insumos, o processo acontece de forma mais natural e consequentemente mais lenta, fazendo com que o cultivo possa apresentar perdas produtivas com pragas e doenças, uma vez que o uso de defensivos naturais não é tão eficaz quanto o agroquímico, mesmo sendo mais saudável, podendo resultar no aumento do valor do alimento, e respectivamente no preço de comercialização, já que esse processo mais lento e com mais perdas aumenta o seu valor de mercado, em comparação ao convencional.

Apesar das limitações, o alimento orgânico se apresenta como uma alternativa saudável para o consumidor, por isso nos últimos 20 anos houve uma expansão em todo o Brasil, do consumo e da produção de alimentos orgânicos, sendo os estados do Sul (Paraná, Santa Catarina e Rio Grande do Sul) os que mais se destacaram no consumo desses produtos e se apresentaram como principais expoentes também em produção (Organis, 2019).

A produção de alimentos orgânicos no Oeste do Paraná ainda é bastante discreta, tendo em vista a pouca quantidade de agricultores orgânicos na região, porém o número de agricultores certificados vem evoluindo, resultado de um processo de

\footnotetext{
${ }^{1}$ O movimento de modernização da agricultura que se iniciou na década de 1970 e está presente até a atualidade, processo conhecido como Revolução Verde, gerou resultados negativos para a classe camponesa, já que o Estado incentivava a compra de maquinário tecnológico e adubos químicos aos grandes latifundiários, fortalecendo sua força econômica e política, os efeitos disso foram diversos, como por exemplo, a expulsão e a expropriação do campo, e a invisibilidade em detrimento ao agricultor de grande porte.
} 
contribuições importantes tanto em escala da unidade familiar produtiva, quanto de organização social e de políticas públicas de incentivo (Corbari, 2020).

Os produtores de alimentos orgânicos representam uma resistência contra hegemônica à agricultura convencional, e são agentes sociais mobilizadores na busca pela sustentabilidade ambiental, porém, apesar das conquistas já obtidas, ainda precisam ser conhecidos e valorizados pela sociedade. Estes apontamentos contrários às forças dominantes, que é representada pela agricultura convencional, são definidos por Polanyi (2000) como "contramovimentos", onde o desenvolvimento rural traduz processos instituídos pelos atores sociais nas localidades ou territórios inscritos nas próprias contradições do capitalismo. Além disso, os agricultores orgânicos são os principais responsáveis pela segurança alimentar dos municípios brasileiros (IBGE, 2017), porém mesmo assim não são valorizados e respeitados pelo Estado e sociedade, em relação ao produtor convencional,.

Nesse sentido, estabeleceu-se a seguinte questão a ser respondida: qual o perfil dos produtores de alimentos orgânicos da cidade de Marechal Cândido Rondon? Para responder essa pergunta, esse trabalho teve como objetivo caracterizar os agricultores que possuem produção orgânica certificada, na cidade de Marechal Cândido Rondon/PR através do Censo agropecuário de 2017. Tendo como objetivos específicos a analise dos estabelecimentos agropecuários com certificação orgânica do município.

Esse artigo está segmentado em cinco partes. Além da introdução, o texto apresentará os materiais e métodos da pesquisa, com uma análise sobre a estrutura geográfica de Marechal Cândido Rondon, sua história e a sua agricultura; na terceira parte será apresentado um referencial teórico sobre produção orgânica e certificação orgânica; nos resultados e discussões, parte quatro do artigo, será revelada a caracterização de seus estabelecimentos agropecuários e as características dos produtores orgânicos, além de uma discussão com a literatura esse modelo de produção; e por fim na quinta parte, será encontrada as considerações finais, atendendo aos objetivos do estudo.

\section{Metodologia}

\subsection{Instrumentos Metodológicos}

Esse trabalho tem natureza qualitativa, e foi dividido em duas etapas: uma análise de dados secundários e uma revisão bibliográfica. Foi realizada uma análise de dados secundários oriundos do Censo Agropecuário de 2017, divulgado pelo Instituto Brasileiro de Geografia e Estatística (IBGE), e do Cadastro Nacional de Produtores Orgânicos, difundido pelo Ministério de Agricultura, Pecuária e Abastecimento (MAPA), sendo a base para a caracterização dos agricultores orgânicos em Marechal Cândido Rondon. Para a analise de dados secundários foi realizado um recorte geográfico, focando nossa observação para a cidade de Marechal Candido Rondon/PR e através do programa Excel foi sendo filtradas as informações necessárias. Além disso, foi realizado um levantamento bibliográfico sobre alimentos orgânicos e certificação, buscando compreender de maneira teórica esses sistemas.

O Censo Agropecuário tem divulgação quinquenal, porém por cortes no orçamento do governo, não existe uma periodicidade na ida ao campo para a pesquisa, além disso, existe também um adiamento na pesquisa, por exemplo, o Censo Agropecuário de 2006 era para ter sido divulgado em 2005, e o último divulgado em 2017, era para ter sido divulgado em 2015. De acordo com Vieira Filho (2020), a pesquisa demonstra as transformações produtivas na agricultura brasileira, desde 1920 no seu ano inaugural até a atualidade.

Além da análise de dados secundários, ainda foi realizada uma pesquisa bibliográfica a fim de identificar os principais desafios e limitações da agricultura orgânica, na intenção de relacionar os dados em Marechal Cândido Rondon com os fatores já descritos em outros estudos. É importante destacar que a pesquisa bibliográfica de caráter exploratório deixa o pesquisador mais próximo ao problema, resultando assim no aprimoramento das suas ideias, sendo esse meio de pesquisa relevante para 
entender o limítrofe que deseja desenvolver (Gil, 2007; Webster \& Watson, 2002).

Para conclusão do texto foram ainda realizadas entrevistas estruturadas com profissionais do IBGE, no intuito de solucionar algumas dúvidas sobre o Censo analisado na pesquisa. As perguntas realizadas foram: O que o IBGE considera produção orgânica nas suas pesquisas? O IBGE considera que os estabelecimentos agropecuários orgânicos são apenas aqueles com certificação? As entrevistas foram realiza de maneira virtual, devido à pandemia do COVID, e aconteceram durante o mês de Junho de 2020.

\subsection{Caracterização geográfica e histórica de Marechal Cândido Rondon/PR}

O município de Marechal Cândido Rondon está localizado na região Oeste do estado do Paraná (24³3'21"S, $\left.54^{\circ} 3^{\prime} 25^{\prime \prime} \mathrm{W}\right)$, fazendo limite com os municípios de Mercedes, Nova Santa Rosa, Quatro Pontes, Toledo, Ouro Verde do Oeste, Pato Bragado, São José das Palmeiras e Entre Rios do Oeste (IBGE, 2010).

A sua história é relativamente recente, sendo criado no ano de 1960. O povoamento surgiu a partir da exploração da erva-mate por ingleses e espanhóis, porém com a presença da Coluna Prestes ${ }^{2}$ na região, esse povoamento foi enfraquecido. Após esse período, a Industrial Madeireira Colonizadora Rio Paraná S/A - MARIPÁ comprou fazendas na região e começou a colonizá-la com a venda de terras para gaúchos e catarinenses, fazendo com que nos anos 50 acontecesse uma migração sulista nessa região do Paraná, onde não somente trouxeram pessoas, mas suas tradições e costumes.

A cidade tem população estimada de 52.944 mil habitantes. Segundo o Censo de 2010, quando tinha uma população de 46.819 habitantes, 39.147 viviam na zona urbana e 7.672 na zona rural (IBGE, 2010), apresentando um grau de urbanização de $83 \%$ (IPARDES, 2017).

O relevo do município também favorece o desenvolvimento agropecuário, apresentando 15\% de áreas planas, 45\% de áreas levemente onduladas, 30\% ondulado e 10\% com forte ondulação (Moresco, 2007). Além de uma contextualização geográfica e histórica é importante analisar a origem e a evolução na agricultura de Marechal Cândido Rondon, para que assim seja possível obter mais subsídios nas discussões posteriores.

\subsection{Histórico da Agricultura em Marechal Cândido Rondon}

Marechal Cândido Rondon dispõe como base econômica as atividades agropecuárias, segundo dados de Magalhães (2006) os solos do município são considerados férteis (terra roxa), ideais para produção agrícola. Sua história como agricultura alimentícia inicia-se com um caráter de subsistência, onde o autoconsumo era o principal destino da produção, porém, a partir dos anos 70 houve uma modernização da agricultura, muito vinculada à Revolução Verde, com a inserção da cultura de grãos (trigo, milho e soja). Até hoje essas culturas são as mais importantes no município, pois esse foi um marco para que ocorresse uma centralidade da cidade em torno da região (Colognese, Gregory \& Schallenberger, 1999; Colognese \& Stoffel, 2007; Stoffel, 2004). Tal produção foi agregada com intensa produção de proteína animal para exportação e hoje essas culturas servem basicamente para esse fim.

Essa produção em monocultura evoluiu em produtividade em todos os anos, de acordo com IBGE (2018) a área ocupada com produção permanente e temporária no município chega a 60.106 hectares, sendo cultivados 31.500 hectares com soja. A região oeste é a que mais se aplica agrotóxico no estado do Paraná (IPARDES, 2010), e na contramão a isso, o consumo, produção e comercialização de orgânicos em Marechal Cândido Rondon vêm evoluindo. Muito disso vem do antagonismo de

\footnotetext{
${ }^{2}$ A Coluna Prestes foi uma revolta tenentista, dentro do movimento militar, ocorrido na década de 1920, que tinha como objetivo tirar do poder os representantes oligárquicos da República Velha. A origem da coluna aconteceu com a fuga dos tenentes que participaram da Revolução de 1924, não conseguindo resistir ao governo federal, realizaram uma marcha pelo interior do Brasil que percorreu 24 mil quilômetros até fevereiro/março de 1927 (Fausto, 2013).
} 
movimentos sociais rurais e da sociedade na contraposição da hegemônica agricultura convencional, entendendo que os resultados desse sistema podem gerar males, tanto para o ambiente quanto para a saúde humana.

Segundo Colognese, Gregory e Schallenberger (1999):

a agricultura familiar para autoconsumo e comercialização de excedentes na região Oeste do Paraná, inicia um processo de transformação na década de 1970, quando a produção local de alimentos tradicionais como arroz, feijão, batata e mandioca passa a ser substituída pela produção de soja e milho. Apesar dos problemas relativos à reprodução socioeconômica, isso não significou um abandono, extinção ou ruptura com a forma de produção tradicional anterior, mas em uma readaptação, que ainda hoje resiste em algumas propriedades por meio da produção de hortaliças, frutas, produtos de panificação, embutidos, ovos, hortifrúti em geral, mel, vinho, queijos, erva-mate, bolachas, melado, açúcarmascavo. Esses produtos são para o autoconsumo e o excedente é comercializado nas feiras locais (Apud Lima, 2019, p.5).

Porém, segundo Gregory (2002), apesar de uma oposição desde os anos 70 à modernização da agricultura convencional na cidade, muitos dos filhos dos agricultores de pequeno porte não viram oportunidades no campo e migraram para a sede do município ou para novas oportunidades de colonização, em cidades de estados novos como Mato Grosso do Sul e Mato Grosso. Essa resposta ao período de revolução verde é encontrada por diversos autores em suas pesquisas.

Entender a agricultura orgânica como resistência possibilita caracterizar o agricultor orgânico do município de Marechal Cândido Rondon, buscar conhecer suas características e seus anseios, além de visibilizá-los como um ponto importante dentro de um universo convencional que eles habitam.

\section{Referencial teórico}

\subsection{Produção orgânica}

A história da humanidade é ligada a agricultura convencional, um meio de produção com caráter produtivista no qual apenas busca a produtividade e consequentemente o lucro, porém a partir do início do século XX a sociedade começa a entender que os resultados desse modelo de agricultura não gerarão resultados positivos.

Na década de 1920 surgiram as primeiras formas de agricultura alternativa. Na Europa a-agricultura orgânica era conhecida muito antes dos efeitos nocivos produzidos pela agricultura industrial que levou à perda da biodiversidade decorrente do uso indiscriminado de pesticidas pela agricultura convencional. Foi nos países de língua alemã que se desenvolveram as primeiras instituições de pesquisa da agricultura orgânica como contra-modelo à industrialização ('quimização', capitalização e racionalização) da agricultura no período entre as guerras, meados da década de 1920 (Schindecker, 2015). Conforme Andreas Attila de Wolinsk Miklos, da Escola Superior de Agricultura Luiz de Queiroz (ESALQ), Universidade de São Palo (USP):

A agricultura biodinâmica tem sua origem na Antroposofia, sob o impulso de Rudolf Steiner. A fonte antroposófica da agricultura biodinâmica108 materializou-se no curso agrícola Fundamentação da Ciência do Espírito para a prosperidade da agricultura, ministrado em Koberwitz, em 1924, sob a forma de oito conferências. Tal curso surgiu em decorrência do questionamento de um grupo de agricultores da Europa Central, preocupados com os problemas ambientais e sociais da agricultura que surgiram após a Primeira Guerra Mundial, suscitando, então, junto a Steiner, novas perspectivas para a agricultura no futuro (Miklós, 2019 p. 71).

A agricultura orgânica teve seu desenvolvimento apoiada em estudos científicos como a biologia, a química, a medicina, a nutrição e as ciências humanas, e seu valores éticos se constituem por quatro princípios definidos pela IFOAM e, assim descritos por Sylvia Maria Schindecker:

- Princípio da saúde: “A agricultura orgânica visa melhorar a saúde dos solos, plantas, animais, humanos e o planeta como um todo e preservando e fortalecendo o indivisível."

- Princípio da ecologia: "A agricultura orgânica deve ser baseada na vida e construir ecossistemas e ciclos, trabalhar com 
Research, Society and Development, v. 10, n. 14, e405101422071, 2021

(CC BY 4.0) | ISSN 2525-3409 | DOI: http://dx.doi.org/10.33448/rsd-v10i14.22071

eles, imitá-los e fortalecê-los".

- Princípio da justiça: "A agricultura orgânica deve ser baseada nas relações que visam construir e garantir justiça no que diz respeito ao ambiente comum e oportunidades iguais na vida."

- Princípio do cuidado: "A agricultura orgânica deve ser realizada de forma preventiva e operada com responsabilidade pela saúde preservando o bem-estar das gerações presentes e futuras e proteger o ambiente em seu entorno." (Schindecker, 2015, p. 3).

Segundo a doutora em Agronomia, Andrea Beste ${ }^{3}$, há centenas de estudos que têm trazido modelos comparativos internacionais, nacionais e regionais, sobre a superioridade da agricultura orgânica em todas as áreas que representam uma agricultura sustentável.

Beste cita um estudo de 40 anos realizado por Reganold, J. e Wachter, J. (2016) que traçam um quadro comparativo entre a agricultura convencional e a agricultura orgânica. A Figura 1, abaixo, apresenta a comparação entre os métodos de cultivo tradicional e orgânico, testificando que a Agricultura orgânica (bio, eco, orgânica) é o único método que alcança os desafios e metas internacionais de sustentabilidade virificáveis (Beste, 2020).

Figura 1 - Avaliação da agricultura orgânica em relação à agricultura convencional nas quatro principais áreas da sustentabilidade.

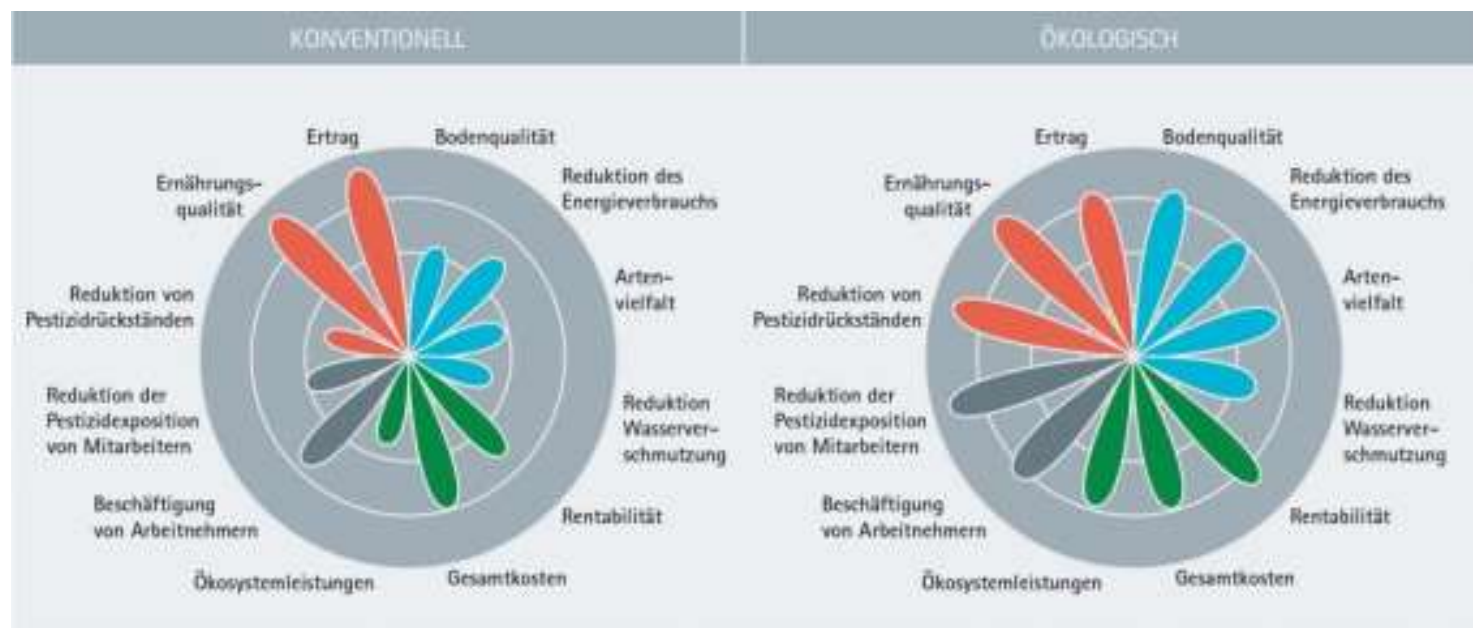

Fonte: BESTE, (2020, p. 3.)

Segundo Coelho (1999) o manejo orgânico surge no Brasil no final dos anos 70, ainda em pequena escala em comparação com a produção convencional, mas começa a evoluir na década de 1990 com a criação do Instituto Biodinâmico de Desenvolvimento Rural (IBD), que muito colaborou para a percepção positiva da sociedade quanto a produção e consumo de orgânicos, com a implementação de projetos de certificação dos produtos agroalimentares.

Como foi apontado anteriormente, a produção orgânica em sua forma de manejo começou a ser debatida nos anos 70 , porém apenas nos anos 90 é intensificada no Brasil, e só foi reconhecida pelo estado em meados dos anos 2000, quando diversas entidades rurais, como MST e CONTAG começaram a manifestar o desejo de visibilizar os agricultores familiares, que naquele momento histórico eram acentuadamente marginalizados em detrimento a agricultura convencional.

Nos 14 anos posteriores ao ano 2000, o Estado começa a entender a importância e a necessidade de ofertar fomento a esses agricultores por meio de políticas públicas, seja de crédito rural, de processos produtivos ou de comercialização (Grisa \& Schneider, 2015), como a Política Nacional de Agroecologia e Produção Orgânica (PNAPO) e o Plano Nacional de Agroecologia e Produção Orgânica (PLANAPO). No contexto da sustentabilidade, mesmo a agricultura de produção orgânica sendo um

${ }^{3}$ https://www.gesunde-erde.net/das-buero/dr-andrea-beste/. 
conceito bastante difundido entre os pesquisadores, por muitas vezes não é colocado em prática, pois é uma experiência que vem contra a hegemonia convencional a qual fomos impostos (Campanhola \& Vilarini, 2001).

Ormond (2002), em relatório destinado ao Banco Nacional de Desenvolvimento (BNDES), assim define a agricultura orgânica:

A agricultura orgânica é entendida como um conjunto de processos de produção agrícola que parte do pressuposto básico de que a fertilidade é função direta da matéria orgânica contida no solo. A ação de microrganismos presentes nos compostos biodegradáveis existentes ou colocados no solo possibilita o suprimento de elementos minerais e químicos necessários ao desenvolvimento dos vegetais cultivados. Complementarmente, a existência de uma abundante fauna microbiana diminui os desequilíbrios resultantes da intervenção humana na natureza e a alimentação adequada e ambiente saudável resultam em plantas mais vigorosas e mais resistentes a pragas e doenças. (Ormond, 2002, p. 5).

Dentro do universo do produto orgânico, está a agroecologia, que pode ser definida como o uso de técnicas em consonância com a sustentabilidade, além disso, existe dentro dessa área uma importância não somente com o ambiente e com o não uso de agrotóxicos, mas com as dimensões social, econômico e cultural do produtor (Clark et al, 2016).

Um dos pontos importantes no desenvolvimento da agricultura orgânica é que ela representa uma agricultura saudável, tanto para o meio ambiente como para o ser humano, e a sua produção tem estreita ligação com a agricultura familiar, pois tem sido uma forte geradora de renda para esses produtores de pequeno porte. Anualmente as demandas por produtos orgânicos evoluem em torno de 30\% no nosso país, e dentro desse percentual, 90\% é originária da agricultura familiar (IPEA, 2012).

A compra de produtos orgânicos além de fortalecer economicamente o agricultor familiar, é saudável para o consumidor e para o ambiente. É necessário entender esse processo de evolução dos orgânicos, não somente como uma atividade produtiva, mas como uma atividade social, que pode resultar no desenvolvimento. Analisar a produção orgânica perpassa em avaliar o processo de certificação orgânica, pois se notou necessário uma verificação quanto às normas estabelecidas pelo Ministério da Agricultura, Pecuária e Abastecimento, principalmente quando o alimento orgânico se tornou um produto de valor agregado (Moraes \& Oliveira, 2017).

De acordo com Ormond (2002, p.28), “a cadeia produtiva dos orgânicos pouco se diferencia das demais cadeias agroalimentares, a não ser pela presença da figura da certificação e, o mais interessante, pela inexistência da figura do atacadista ou do intermediário entre a produção e o elo seguinte". A certificação serve então como um meio de provar a qualidade dos produtos orgânicos e com isso aumentar a credibilidade com os consumidores.

\subsection{Certificação orgânica}

Analisa-se que "a certificação de produtos orgânicos constitui-se de uma série de procedimentos estabelecidos e acordados entre agricultores [...] e consumidores que garantem que bens ou serviços foram produzidos de forma diferenciada dos demais" (Brancher, 2004, p.3). O processo de certificação surgiu no ano de 1998, muito devido à pressão de ativistas voltados ao universo rural (Fonseca, 2005), pois foi notada a necessidade de garantir ao consumidor que a produção dita orgânica, está realmente de acordo com as normas dos processos de produção sustentável. Segundo Campanhola e Vilarini (2001, p 9) “a certificação de produtos orgânicos visa conquistar maior credibilidade dos consumidores e conferir maior transparência às práticas e aos princípios utilizados na produção orgânica”.

As normas que delimitam a agricultura orgânica foram publicadas em 28 de dezembro de 2007, pelo decreto 6.323, regulamentando a Lei 10.831/2003 (Cardoso, 2009). Esse modelo de agricultura por muito tempo foi entendido como burocrático e caro pelos agricultores familiares, porém o mesmo consegue agregar valor ao produto, se inserir em políticas públicas e receber maiores créditos financeiros. 
Segundo o Lima (2020, p.28), “constata-se um crescimento médio anual de 19\% de unidades de produção orgânica, entre 2010 e 2018, e um aumento médio anual de quase $17 \%$ do número de produtores orgânicos registrados no Mapa nos últimos sete anos no país". Este crescimento também torna mais evidente uma cobrança dos consumidores com relação a qualidade e veradicidade orgânica dessa produção. Em paralelo a isso, devido as inquietações dos pequenos produtores, aconteceu uma evolução nas formas de certificação e consequentemente uma diminuição do valor dessa atividade. De acordo com Brasil (2019), existem três mecanismos de certificação no Brasil, com isso o agricultor orgânico é cadastrado no Cadastro Nacional de Produtores Orgânicos, são eles:

Certificação por Auditoria - A concessão do selo SisOrg é feita por uma certificadora pública ou privada credenciada no Ministério da Agricultura. O organismo de avaliação da conformidade obedece a procedimentos e critérios reconhecidos internacionalmente, além dos requisitos técnicos estabelecidos pela legislação brasileira.

Sistema Participativo de Garantia - Caracteriza-se pela responsabilidade coletiva dos membros do sistema, que podem ser produtores, consumidores, técnicos e demais interessados. Para estar legal, um SPG tem que possuir um Organismo Participativo de Avaliação da Conformidade (Opac) legalmente constituído, que responderá pela emissão do SisOrg.

Controle Social na Venda Direta - A legislação brasileira abriu uma exceção na obrigatoriedade de certificação dos produtos orgânicos para a agricultura familiar. Exige-se, porém, o credenciamento numa organização de controle social cadastrado em órgão fiscalizador oficial. Com isso, os agricultores familiares passam a fazer parte do Cadastro Nacional de Produtores Orgânicos (MAPA, 2020).

Os mecanismos de certificação estão cada vez mais exigentes devido à cobrança do público consumidor e do valor agregado ao produto na comercialização. É notado que o caráter econômico é uma das principais motivações para a certificação, porém muitos agricultores ainda não têm a percepção quanto aos contextos ambientais que isso representa.

\section{Resultados e discussão}

\subsection{Caracterização dos Estabelecimentos Agropecuários de Marechal Cândido Rondon/PR}

O município de Marechal Cândido Rondon apresenta um total de 1.934 estabelecimentos agropecuários, dentre estes, $1.540(79,6 \%)$ apresentam uma agricultura familiar e 394 (20,4\%) não familiares, conforme mostra a Tabela 1.

Tabela 1 - Estabelecimentos agropecuários de Marechal Cândido Rondon.

\begin{tabular}{c|c}
\hline Estabelecimentos agropecuários (Total) & 1.934 \\
\hline Agricultores familiares & 1.540 \\
\hline Agricultores não familiares & 394 \\
\hline
\end{tabular}

Fonte: Organizado pelos autores através de dados do IBGE (2017).

Esse número elevado de agricultores familiares é contrário à média do Paraná, estado que apresenta uma das menores porcentagens de agricultores familiares do país com 23,5\% (IBGE, 2017), esse resultado está vinculado ao processo de desenvolvimento econômico que aconteceu e ainda acontece no estado, ligado ao agronegócio. Dentro desse universo de 1.540 estabelecimentos agropecuários familiares no município, foi analisado que 321 nunca utilizaram agrotóxicos em sua produção, isso representa 20,8\% da agricultura familiar de Marechal Cândido Rondon, como é observado na figura 1. A produção convencional, representada pelo uso de agrotóxicos é muito forte dentro da agricultura familiar da cidade, representando 78\% dos estabelecimentos. Vale aqui ressaltar a diferenciação entre esses dois conceitos que muitas vezes são somados, pois a agricultura familiar nem sempre é orgânica, e a produção orgânica nem sempre é familiar, elas são divididas de acordo com o modelo e a finalidade de produção. 
Research, Society and Development, v. 10, n. 14, e405101422071, 2021

(CC BY 4.0) | ISSN 2525-3409 | DOI: http://dx.doi.org/10.33448/rsd-v10i14.22071

Quando se fala em agricultura não-familiar, dos 394 estabelecimentos agropecuários que o município apresenta, 123 $(31,2 \%)$ nunca utilizaram agrotóxico, ou seja, a porcentagem de estabelecimentos que nunca utilizou agrotóxico é maior na agricultura não familiar do que na familiar, como é analisado na Figura 2.

Figura 2 - Uso de agrotóxicos nos estabelecimentos agropecuários de Marechal Cândido Rondon.

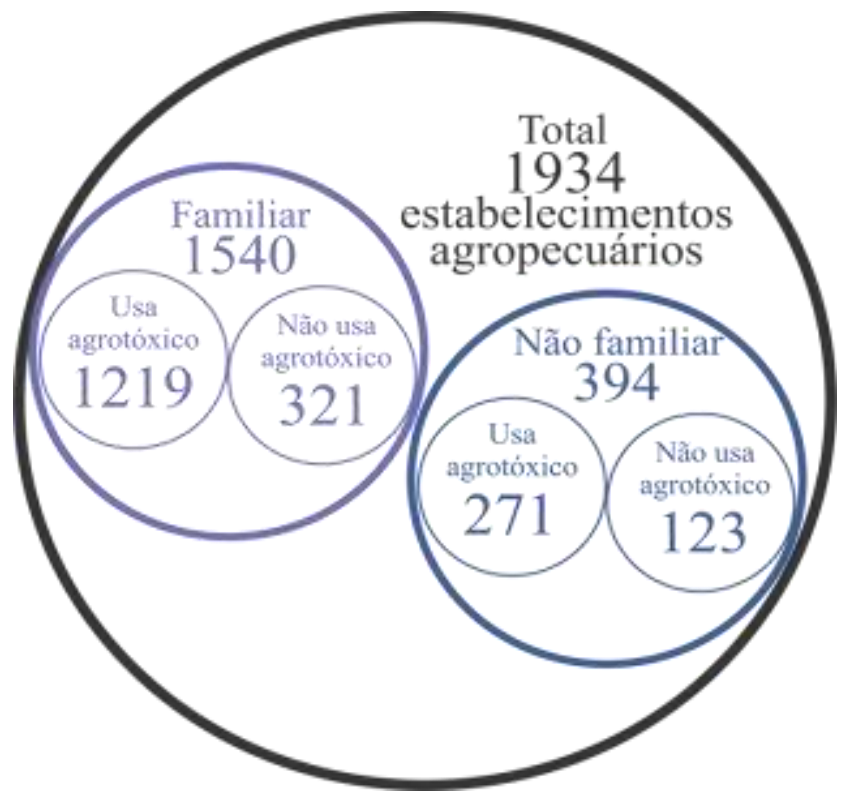

Fonte: Organizado pelos autores através de dados do IBGE (2017).

Esses dados revelam que a cidade de Marechal Cândido Rondon vive uma crise bastante dura, onde 75,8\% dos estabelecimentos agropecuários, sejam eles familiares ou não, usam agrotóxicos em suas lavouras, em um total de 1.482 unidades de produção. Assim, apesar do elevado número de estabelecimentos familiares, eles não diferem dos agricultores não familiares pelos seus processos de produção, mas por outras características como tamanho da propriedade e contratação de funcionários.

Os serviços de Assistência Técnica e Extensão Rural são realizados em 71,60\% das propriedades do município, porém esse serviço é apresentado com caráter apenas produtivo na maioria dos casos, pensando apenas na produção final e consequentemente no lucro e não na sustentabilidade, fazendo com que a evolução no consumo de agrotóxicos de 2006 até 2017 fosse elevada. Sem um pensamento ambiental e social, o extensionista rural apenas serve como um transmissor de informações, que não é acompanhado de um pensamento interdisciplinar e multidisciplinar na busca pelo desenvolvimento rural.

\subsection{1 Área de produção}

Conforme observado no Gráfico 1, que nos mostra a área total dos estabelecimentos no município de Marechal Cândido Rondon, foi analisado que as propriedades tem área entre 0,01 à 500 hectares (ha). 
Research, Society and Development, v. 10, n. 14, e405101422071, 2021

(CC BY 4.0) | ISSN 2525-3409 | DOI: http://dx.doi.org/10.33448/rsd-v10i14.22071

Gráfico 1 - Área total dos estabelecimentos agropecuários de Marechal Cândido Rondon.

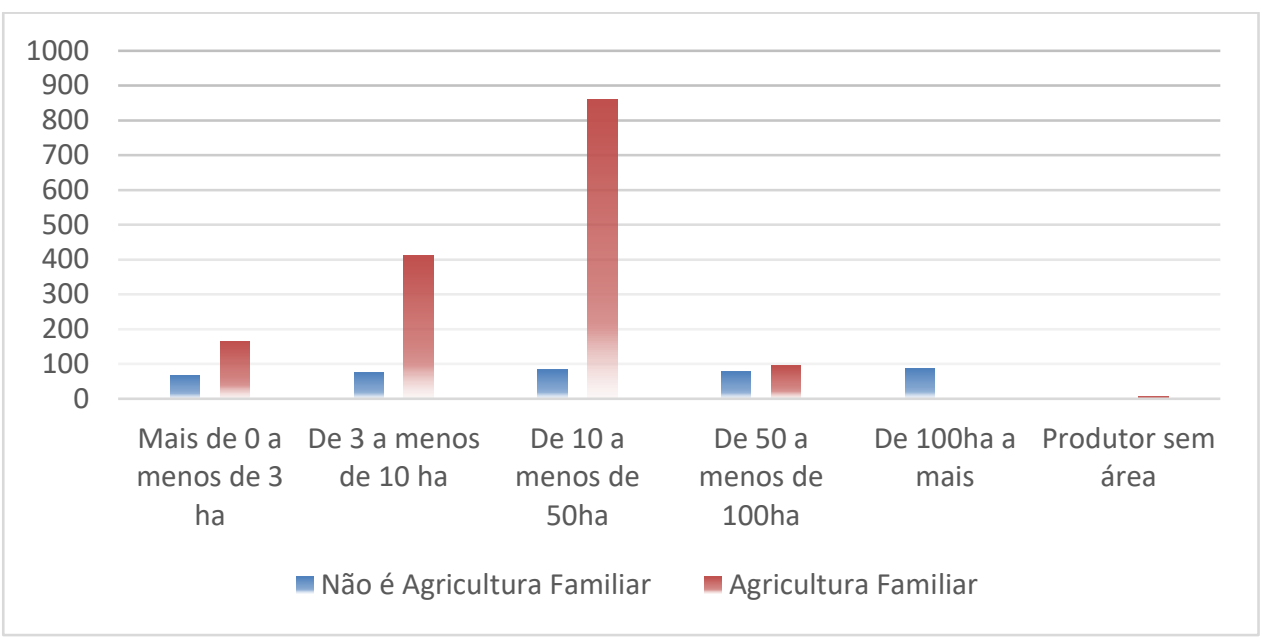

Fonte: Organizados pelos autores através de dados do IBGE (2017).

Ainda analisando o gráfico 1, é importante registrar que existe uma maior porcentagem de estabelecimentos rurais com áreas de 20 a 50 ha no município, sendo esses considerados estabelecimentos de pequeno porte para a região. Quando é referida a agricultura familiar foi analisado um maior índice de áreas com 10 a 20 ha, mostrando uma predominância dessa classe em estabelecimentos menores. Os estabelecimentos para serem considerados familiares precisam ter até quatro módulos fiscais e esses são diferentes em cada estado do Brasil. No Paraná o módulo fiscal tem 18 ha podendo um agricultor familiar, para possuir esse título, ter até 72 ha.

O município ainda apresenta 86 estabelecimentos com áreas entre 100 a 500 ha. Essas grandes propriedades são típicas no Paraná e na sua maioria, são produtores de soja e milho. Marechal Cândido Rondon se caracteriza como um dos maiores produtores de milho e soja do Brasil (IBGE, 2017).

\subsubsection{Gênero}

Dos 1.934 estabelecimentos agropecuários em Marechal Cândido Rondon, 1.752 (90,5\%) são administrados por homens e $175(09,5 \%)$ por mulheres (Tabela 2), mostrando enorme disparidade ainda existente entre gênero no meio rural. A mulher ainda se encontra invisível no universo rural, servindo apenas como uma ajudante, em um sistema patriarcal (Vergutz, 2020).

Tabela 2 - Administração por gênero nos estabelecimentos agropecuários de Marechal Cândido Rondon.

\begin{tabular}{c|c}
\hline Estabelecimentos agropecuários (Total) & 1.934 \\
\hline Administrados por homens & $1.752(90,5 \%)$ \\
\hline Administrados por mulheres & $175(09,5 \%)$ \\
\hline
\end{tabular}

Fonte: Organizado pelos autores através de dados do IBGE (2017).

Segundo dados do (IBGE, 2017) houve um aumento de participação do sexo feminino entre os produtores no Brasil, de 12,7\% em 2006 para 18,6\% em 2017, essa alteração também aconteceu no município estudado, que passou de 160 em 2006 (IBGE, 2006) para 175 em 2017, tendo um aumento de 10,9\%, fruto de diversas políticas públicas que incentivavam a participação das mulheres na agricultura.

Quando falamos apenas em agricultura familiar, a mesma disparidade também é apresentada, sendo que em 1.540 
Research, Society and Development, v. 10, n. 14, e405101422071, 2021

(CC BY 4.0) | ISSN 2525-3409 | DOI: http://dx.doi.org/10.33448/rsd-v10i14.22071

estabelecimentos classificados como familiar na cidade, apenas $137(08,9 \%)$ são administrados por mulheres. As mulheres por muitas vezes são tidas como ajudantes e não como profissionais, com isso o processo de masculinização está cada vez maior no campo, devido a migração dessas mulheres para o meio urbano em busca de melhores oportunidades, tendo em vista que ainda se apresenta no meio rural um problema da falta de estrutura, seja ela educacional, econômica ou social (Leal, 2018). Outro ponto a ser considerado na relação entre produção e os estabelecimentos agropecuários é a escolaridade.

\subsubsection{Escolaridade}

A escolaridade também evoluiu em relação ao último censo apresentado em 2006. A juventude, que aqui pode ser entendida como uma classe com idade até 35 anos está cada vez mais alfabetizada e crescendo em escolaridade em relação aos mais velhos, isso fruto de diversas políticas públicas educacionais que incentivam a educação no campo. A maioria dos agricultores (47\%) administradores dos estabelecimentos possuem apenas o ensino primário completo, esses dados vão de acordo com a média do Brasil, onde a escolaridade ainda representa uma dificuldade, devido às condições sociais que estamos inseridos.

Algumas pesquisas (Hoffmann \& Gomes Ney, 2004; Vicente, Anefalos \& Caser, 2003) já evidenciam a relação entre o desenvolvimento da agricultura e os altos níveis de escolaridade dos produtores. Os agricultores com maiores escolaridades conseguem desenvolver mais facilmente as adequações técnicas e produtivas e a gestão fornecida por órgãos públicos, buscando a sua inserção em políticas públicas (Troiano, 2015). Segundo Paula (2019, p.8) em pesquisa realizada nos estados da região Sul do Brasil, "a hipótese de que a escolaridade de pessoas que residem e trabalham em zonas rurais da região Sul tem efeito positivo sobre a produção de seus principais produtos agrícolas é válida". A educação tem uma relação intrínseca com o futuro dos agricultores, tendo em vista que com mais conhecimento também surge novas oportunidades, sejam elas produtivas ou econômicas.

No Brasil, pela sua heterogeneidade, se consegue analisar regiões com altos níveis de escolaridade e outras com baixo nível, além do abismo que acontece entre o urbano e o rural. Para essa análise são importantes os indicadores, que conseguem caracterizar a educação no país. O Índice de Desenvolvimento Humano Municipal (IDHM) usa três dimensões para medir o desenvolvimento: longevidade, educação e renda. O IDHM Educação é a medida de dois indicadores: escolaridade da população adulta e fluxo escolar da população jovem. Os estados do Sul apresentam valores considerados altos em relação ao Brasil e principalmente aos estados do Nordeste e Norte, que representam as menores médias (Atlas Brasil, 2020).

O Paraná em relação ao Brasil, tem a $5^{\circ}$ melhor média de IDHM Educação com 0,668, no Sul, fica atrás apenas de Santa Catarina, que ocupa a $3^{\circ}$ posição com 0,697 no Brasil. O município de Marechal Cândido Rondon tem média alta com 0,774, esses dados não corroboram com encontrado no Censo Agropecuário de 2017, pois a média do IDHM Educação não tem separação entre urbano e rural, podendo o valor do primeiro elevar a média geral do município (Atlas Brasil, 2020). A baixa escolaridade dos administradores dos estabelecimentos agropecuários do município é considerada um resultado importante para entender a sua produção de alimentos orgânicos certificada.

\subsection{Produção orgânica em Marechal Cândido Rondon/PR}

No Censo Agropecuário de 2017, foi entendida como produção orgânica, segundo entrevista com funcionários do IBGE, apenas as produções certificadas, ignorando assim o uso ou não de agrotóxicos em Marechal Cândido Rondon, dessa forma 47 estabelecimentos produzem alimentos orgânicos, enquanto 1.887 estabelecimentos não possuem certificação, podendo produzir com ou sem agrotóxicos, como analisado na Tabela 3. 
Research, Society and Development, v. 10, n. 14, e405101422071, 2021

(CC BY 4.0) | ISSN 2525-3409 | DOI: http://dx.doi.org/10.33448/rsd-v10i14.22071

Tabela 3 - Produção orgânica nos estabelecimentos agropecuários de Marechal Cândido Rondon.

\begin{tabular}{c|c}
\hline Estabelecimentos agropecuários (Total) & 1.934 \\
\hline Estabelecimentos com produção convencional (não orgânica) & 1.887 \\
\hline Estabelecimentos com produção orgânica (certificação) & 47 \\
\hline
\end{tabular}

Fonte: Organizado pelos autores através de dados do IBGE (2017).

Dentro desses 47 estabelecimentos, 33 são familiares enquanto 14 são não familiares. Apesar da maior porcentagem de produção de alimentos sem utilização de agrotóxicos serem dos estabelecimentos não familiares, é visto que quando falamos em certificação, a classe familiar se sobrepõe, e isso é resultado de uma conscientização desses agricultores e também pela necessidade de certificação para a disponibilidade de fomento e inserção em políticas públicas.

Segundo Campanhola e Valarini (2001), na compra direta, a certificação não é levada em consideração, tendo em vista que já existe uma relação de confiança entre o produtor e os clientes. Essa afirmação condiz com a pouca certificação no município. Miollo (2019) ao realizar pesquisa com agricultores agroecológicos do Rio Grande Sul, cita a burocracia como um dos principais entraves no processo de certificação.

Segundo o Cadastro Nacional de Produtores Orgânicos (CNPO, 2020) entre os 47 agricultores orgânicos de Marechal Cândido Rondon/PR, três entidades realizam o processo de certificação: Associação Ecovida de Certificação Participativa; Instituto de Tecnologia do Paraná (TECPAR); e Ecocert Brasil Certificadora.

A rede Ecovida é a principal certificadora do município apresentando-se com 60\% das certificações (CNPO, 2020), esse grupo de certificação tem destaque no Sul do Brasil com um modelo denominado Sistema Participativo de Garantia, onde diversos agricultores familiares e consumidores garantem o selo de verificação das normas de produção orgânica. É um processo rigoroso, onde é necessária uma conscientização social e ambiental. A certificação acontece através de núcleos regionais, onde ocorrem trocas de saberes e a verificação da produção orgânica, tornando um processo mais democrático e justo (Miollo, 2019).

Ainda segundo Miollo (2019, p. 60):

O funcionamento da Rede Ecovida de Agroecologia é horizontal e descentralizado, está respaldado na organização das famílias produtoras em grupos informais, associações ou cooperativas. Estas organizações se articulam com associações ou cooperativas de consumidores, ONGs e outras instituições e formam um Núcleo Regional, delimitado a determinada área geográfica. Cada Núcleo tem uma coordenação com uma tarefa de animação e gestão.

Segundo a Rede Ecovida (2017) "a credibilidade é gerada a partir da seriedade conferida a todo o processo, partindo da palavra da família agricultora e se legitimando socialmente, de forma acumulativa, nas distintas instâncias organizativas que esta família integra". A Rede está credenciada no Ministério da Agricultura, Pecuária e Abastecimento (MAPA), se tornando um Organismo Participativo de Avaliação de Conformidade Orgânica (OPAC).

De acordo com International Federation of Organic Agriculture Movements (IFOAM, 2008, p. 4) existem algumas evidências que baseiam a prevalência da certificação participativa:

1. Visão compartilhada: Trata-se de um aspecto fundamental na filosofia de um Sistema participativo refletindo a convergência de interesses entre produtores e consumidores em torno dos mesmos princípios, particularmente com relação à consciência ativa sobre o porquê, como e, sobretudo, a quem se busca servir através desse processo;

2. Participação: O Sistema participativo está baseado numa metodologia ancorada na participação dos interessados na produção e consumo deste tipo de produto. Os princípios e regulamentos para a produção ecológica estão concebidos e se aplicam por meio da contribuição de todos os interessados;

3. Transparência: Todos os interessados, incluindo os produtores, devem estar conscientes do modo como funciona o mecanismo de garantia e de como são tomadas as decisões. As pessoas devem estar cientes dos critérios adotados, 
Research, Society and Development, v. 10, n. 14, e405101422071, 2021

(CC BY 4.0) | ISSN 2525-3409 | DOI: http://dx.doi.org/10.33448/rsd-v10i14.22071

especialmente das razões pelas quais uma unidade de produção eventualmente não venha a ser considerada ecológica. O acesso à informação há que ser conjugado com o respeito à privacidade e confidencialidade do processo;

4. Confiança - Enfoque baseado na integridade: Os partidários de um Sistema participativo preservam a ideia de que se pode confiar nos produtores e de que o sistema de certificação de orgânicos deve ser expressão desta confiança.

5. Processo de aprendizagem: O propósito da maioria do Sistema participativo tem sido o de proporcionar muito mais do que um certificado, dado que o objetivo maior é o de oferecer ferramentas e

mecanismos para apoiar o desenvolvimento ecológico das comunidades, melhorando as condições de vida dos próprios.

6. Horizontalidade: Significa dividir o poder. A verificação da qualidade ecológica de um produto ou processo não se apresenta concentrada nas mãos de alguns poucos.

A rede Ecovida é estruturada por núcleos em estados do Brasil, apresentando 26 núcleos regionais, principalmente no sul e sudeste, no Paraná têm-se 8. Esses núcleos são divididos em grupos que tem como uma das funções se reunirem mensalmente, segundo Engelmann (2015) essas reuniões são momentos de troca de experiências e de integração. Um dos principais objetivos da rede Ecovida é o processo de transição orgânica e agroecologia, segundo a própria rede:

A certificação da produção ecológica de propriedades em conversão é permitida desde que: No plano de conversão seja previsto a ecologização progressiva da propriedade agrícola. O tempo de conversão deverá ser estabelecido em comum acordo entre o agricultor e o Núcleo Regional, devendo este tempo ser definido em função das características sócioeconômicas e ambientais de cada região e de cada propriedade (Ecovida, 2004, p. 18).

Existe uma necessidade de fortalecer cada vez mais o processo de certificação na cidade e no Brasil como um todo, apesar da necessidade de políticas rigorosas, é necessário uma maior divulgação das vantagens da alimentação orgânica, tanto para os produtores quanto para os consumidores. Cabe aqui ressaltar que a certificação orgânica fortalece o processo de permanecimento dos agricultores familiares em suas propriedades, esse dado é reforçado por Carlett (2019), que em pesquisa no Oeste do Paraná, em um universo de 20 agricultores, 16 acreditavam que a certificação de produtos orgânicos colabora para a permanência dos agricultores familiares em sua propriedade, diminuindo a transição campo-cidade e favorecendo o desenvolvimento rural.

Diversas políticas públicas incentivam a produção de alimentos orgânicos, no Paraná a principal política da Secretaria de Agricultura e Abastecimento é o Programa Paraná Mais Orgânico, que tem como objetivo orientar agricultores familiares interessados em produzir alimentos de maneira orgânica. O programa funciona através de núcleos e a cidade de Marechal Cândido Rondon através da Universidade Estadual do Oeste do Paraná (UNIOESTE) é sede de um desses, com 10 anos de atuação. Sendo assim, a cidade é um dos principais núcleos da política, cujo programa tem um crescimento contínuo, se tornando um meio eficaz para o desenvolvimento da sustentabilidade na cidade de Marechal Cândido Rondon.

Os produtores têm diversas dificuldades para fazer a transição orgânica, seja pelo seu conhecimento técnico, já que o manejo não convencional ainda é pouco discutido, pelas burocracias da certificação e o valor das mesmas. Porém os pontos positivos sociais, ambientais e econômicos sobrepõem a esses limites.

São necessárias cada vez mais pesquisas e esclarecimentos sobre a necessidade de orgânicos no mundo, levando em consideração o aumento populacional e as crises ambientais, ou seja, entender o orgânico é entender o futuro.

\subsubsection{Produção}

A produção de vegetais orgânicos, principalmente horticultura e fruticultura, se sobrepõem a produção animal, como visto na Tabela 4. Isso está relacionado à dificuldade de produzir animais certificadamente orgânico, pois existem diversas normas a serem seguidas, que muitas vezes o produtor não consegue cumprir. 
Research, Society and Development, v. 10, n. 14, e405101422071, 2021

(CC BY 4.0) | ISSN 2525-3409 | DOI: http://dx.doi.org/10.33448/rsd-v10i14.22071

Tabela 4 - Finalidade da produção orgânica nos estabelecimentos agropecuários de Marechal Cândido Rondon.

\begin{tabular}{c|c}
\hline Estabelecimentos agropecuários (Total) & 47 \\
\hline Vegetais orgânicos & 35 \\
\hline Animais orgânicos & 5 \\
\hline Vegetais e animais & 7 \\
\hline
\end{tabular}

Fonte: Organizado pelos autores através de dados do IBGE (2017).

Dentro de um universo de 47 produtores, 35 deles produzem vegetais orgânicos; 5, animais orgânicos e 7, animais e vegetais orgânicos, esses dados corroboram com a pesquisa de Leonel $(2011$, p. 8) que cita que "a horticultura e fruticultura são as atividades mais praticadas pelos produtores orgânicos de Marechal Cândido Rondon”.

Realizando uma análise sobre a Instrução Normativa $n^{\circ} 64$ de 18 de dezembro de 2008, que dita às normas técnicas nacionais vigentes na produção de animais e vegetais orgânicos, baseada na Lei 10.831 de 23 de dezembro de 2003, fica claro a enorme complexidade nesse processo. Segundo Signor (2011, p. 29) “os sistemas orgânicos de produção orgânica animal devem adotar práticas que visem o bem-estar animal em todas as fases do processo produtivo para que o animal conviva de forma harmoniosa com os outros indivíduos e com o ambiente que está instalado".

Essa complexidade pode ser a resposta do número pequeno de estabelecimentos agropecuários que produzem animais orgânicos em Marechal Cândido Rondon. Outro fator para este resultado é a dificuldade de comercializar animais orgânicos com uma valorização financeira, e isso é explicado pela ausência de espaços de comercialização, levando em consideração os aspectos sanitários.

\subsubsection{Gênero e faixa etária}

Dentre os 47 produtores de alimentos orgânicos, 35 deles são do sexo masculino e 12 do sexo feminino (Tabela 5), disparidade que acontece tanto na produção convencional como na orgânica, segundo Garcia (2016, p. 44) existe “a necessidade de fortalecimento de participação da mulher no meio rural, pois é sabido, que ela tem exercido multipapéis na organização familiar e tem se destacado na gestão dos negócios e geração ou complementação de renda da família”.

Tabela 5 - Administração por gênero nos estabelecimentos agropecuários de Marechal Cândido Rondon que produzem alimentos. Orgânicos.

\begin{tabular}{c|c}
\hline Estabelecimentos agropecuários (Total) & 47 \\
\hline Administrados por homens & $35(74,5 \%)$ \\
\hline Administrados por mulheres & $12(25,5 \%)$ \\
\hline
\end{tabular}

Fonte: Organizado pelos autores através de dados do IBGE (2017).

Mesmo que a participação das mulheres ainda seja discreta, nota-se uma evolução entre a produção convencional $(09,5 \%)$ e a orgânica $(25,5 \%)$, isso demonstra a importância da presença feminina nesse modelo de agricultura.

Diversas pesquisas (Riberio, 2020; Siliprandi, 2015; Til, 2020;) apontam essa importância da mulher para a agricultura orgânica e o processo de sustentabilidade, e citam alguns entraves como a dificuldade em assumir lideranças e a sua desvalorização social no campo, tendo em vista que o machismo ainda é muito frequente, impossibilitando a sua autonomia.

Ainda assim, as mulheres têm uma relação muito forte com a produção de alimentos orgânicos, isso é resultado, segundo 
Research, Society and Development, v. 10, n. 14, e405101422071, 2021

(CC BY 4.0) | ISSN 2525-3409 | DOI: http://dx.doi.org/10.33448/rsd-v10i14.22071

Leal (2018, p. 14), “das suas preocupações com a saúde e alimentação das pessoas e com a preservação do ambiente. São elas as mais afetadas quando ocorrem problemas de saúde com membros da família, pois é sobre elas que recai o trabalho dos cuidados".

Além disso, as mulheres são consideradas importantes vetores sociais para a potencialização da agricultura orgânica, um campo com poucas propriedades administradas por mulheres pode ser uma explicação para o baixo número de produtores de alimentos sem agrotóxicos em Marechal Cândido Rondon. Quando relacionamos esses números à idade, é observado que adultos (45-55 anos) são a faixa etária mais presente entre os agricultores que produzem alimentos orgânicos em Marechal Cândido Rondon/PR.

\subsubsection{Serviços de ATER}

Em revisão de literatura, foi percebido que o Centro de Apoio ao Pequeno Agricultor (CAPA) tem papel primordial para a transição de produtores convencionais para orgânicos e na evolução em relação ao último censo, fazendo um trabalho de extensão rural. O CAPA atua há 19 anos no município e atualmente atende 19 municípios do Oeste paranaense (CAPA, 2021), segundo Leonel (2011, p.4) “atua na organização comunitária, capacitação dos agricultores, assessoria técnica de produção, apoio à agrotransformação e comercialização, atividades essas em parceria com agricultores e outras instituições". O centro como falado anteriormente trabalha com parcerias com outras instituições como por exemplo a rede Ecovida, a qual é contemplado no tópico 4.2.6, importante parceira no processo de certificação dos produtos orgânicos.

Diversas outras entidades atuam ou já atuaram na promoção de alimentos sustentáveis em Marechal Cândido Rondon como a ACEMPRE, MAYTENUS, BIOLABORE E SUSTENTEC, gerando uma rede em busca de sustentabilidade e fortalecendo o agricultor familiar. Além disso, a ITAIPU BINACIONAL com seus projetos de sustentabilidade como o “Cultivando água boa” foram importantes nos processos de produção orgânicas dentro da cidade.

\subsection{4 Área e produção}

Os agricultores orgânicos na cidade ocupam estabelecimentos com pequenas áreas, como mostra o Gráfico 2 , havendo uma prevalência de produtores em minifúndios, com estabelecimentos entre 0,5 e 1 ha, sendo produtores com pequenas áreas, pois é considerado de pequeno porte as propriedades com menos de 4 módulos fiscais, em sua propriedade. 
Gráfico 2 - Área total dos estabelecimentos agropecuários que produzem orgânicos certificados em Marechal Cândido Rondon/PR.

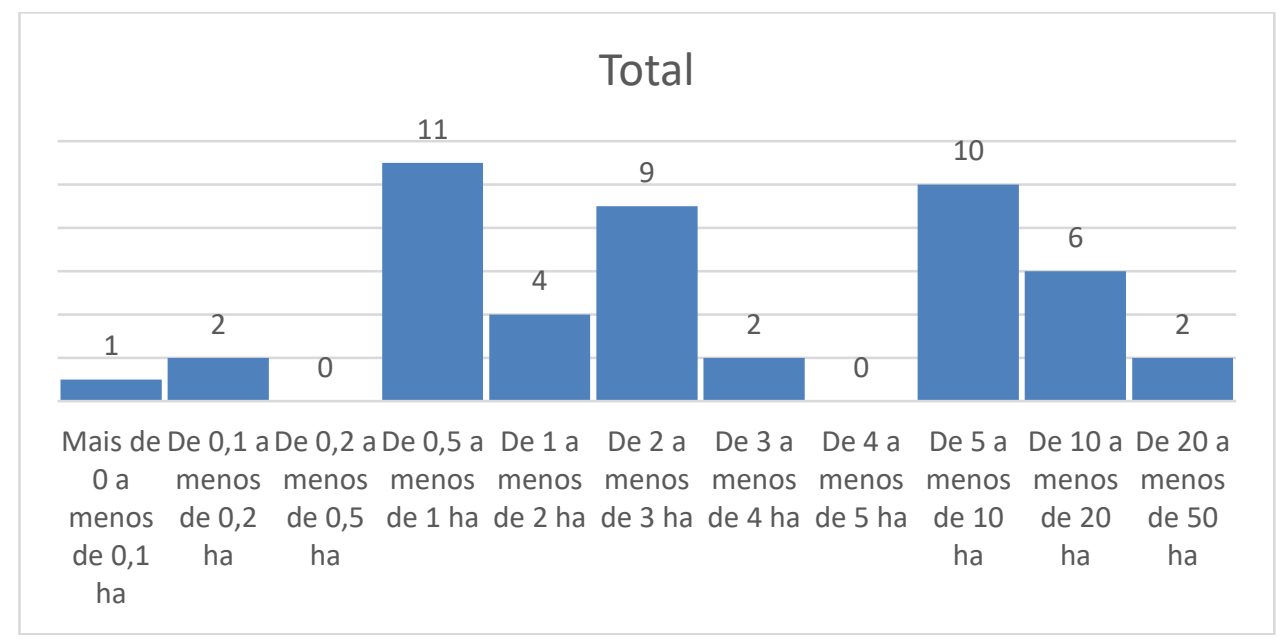

Fonte: Organizado pelos autores através de dados do IBGE (2017).

Nesse contexto, Segundo Engrelmann (2018, p. 50):

O tamanho limitado da área das propriedades faz com que exista uma dificuldade em obter renda apenas de um produto agrícola, aspecto que facilita a busca por outra estratégia produtiva e, desse modo, essas famílias optam por uma variedade maior de produtos a serem plantados e comercializados, uma característica presente na agroecologia, ou seja, a diversificação.

A diversificação também é ocorrente em Marechal Cândido Rondon, segundo o Cadastro Nacional de Produtores Orgânicos em 2020, existem uma diversidade de frutas, verduras e hortaliças certificadas no município.

Cabe aqui ressaltar que a diversidade produtiva de alimentos orgânicos gera o permanecimento de produtores em seus estabelecimentos rurais, fortificando sua economia (Veronezzie \& Bastos, 2012), mas para isso são necessários canais de comercialização cada vez mais efetivos e justos.

\subsubsection{Canais de comercialização}

A produção orgânica em Marechal Cândido Rondon é vendida em diversos canais de comercialização, segundo Garcia (2016, p. 48) “o produto orgânico já é comprado com valor 30\% superior ao produto convencional, assim, o atendimento à legislação, ou seja, a prática de preços diferenciados para os produtos orgânicos motivou a busca dos agricultores pela certificação". A valorização financeira do produto é algo que motiva os produtores na transição para a agricultura orgânica. Um canal de comercialização é a Associação Central dos Produtores Rurais Ecológicos (ACEMPRE), que colabora junto aos agricultores orgânicos na comercialização, seja na sua loja própria, na entrega em supermercados, em feiras rotativas, ou atuando junto às políticas públicas como o Programa Nacional de Alimentação Escolar (PNAE).

O PNAE é uma política pública da década de 50, mas se fortificou com a lei nº Lei 11.947 em 2009, que estabeleceu que pelo menos 30\% dos repasses do Fundo Nacional de Desenvolvimento da Educação (FNDE) na alimentação escolar seriam destinados à agricultura familiar. O programa se tornou um importante circuito curto de comercialização, favorecendo o agricultor, tendo em vista que a comercialização se apresenta como um dos principais entraves no processo de desenvolvimento rural. O PNAE em Marechal Cândido Rondon tem uma lei municipal própria, que projeta em 2021 comprar 100\% da alimentação escolar de agricultores orgânicos (Marechal, 2018). Outro canal de comercialização são as feiras livres, que tem 
tradição junto aos agricultores e aos consumidores rondonienses.

\section{Considerações Finais}

Os agricultores orgânicos de Marechal Cândido Rondon/PR em números, são bastante discretos em relação ao número total de estabelecimentos agropecuários, sendo na sua maioria, agricultores familiares do gênero masculino e com idade entre 45 e 55 anos, certificados pela Rede Ecovida, de maneira participativa, e com o auxílio dos programas de incentivo à produção de alimentos orgânicos.

Tratando-se da prática da agricultura orgânica nos estabelecimentos do município constatou-se que apenas um pouco mais que $2 \%$ produzem alimentos orgânicos. Evidenciando assim os desafios, no que se refere ao acesso ao conhecimento e às condições materiais para a realização da transição agroecológica observa-se necessidade de novos projetos de incentivo à produção de orgânicos e alimentação saudável, com a implantação de sua importância em sistemas de ensino escolar, para que as novas gerações tenham conhecimento dos benefícios de uma alimentação saudável desde os anos iniciais, colocando em primeiro lugar a saúde e não o lucro.

Os dados do IBGE, associados a uma revisão bibliográfica minuciosa, resultaram em um olhar bastante preciso sobre qual a relação entre o município e a produção de orgânicos. Entretanto, cabe ainda destacar a necessidade de mais estudos que demonstrem a realidade empírica dos agricultores e seus sistemas de produção orgânicos, bem como os aspectos que evidenciem a transição a produção sustentável no município.

\section{Agradecimentos}

Agradecimento ao Programa de Pós-Graduação em Desenvolvimento Rural Sustentável - PPGDRS, da Universidade Estadual do Oeste do Paraná - UNIOESTE. Agradecemos à Coordenação de Aperfeiçoamento de Pessoal de Nível Superior CAPES e ao Conselho Nacional de Desenvolvimento Científico e Tecnológico - CNPq pelo financiamento da pesquisa através da bolsa de estudo dos autores. Por fim, também agradecemos ao Grupo Interdisciplinar e Interinstitucional de Pesquisa e Extensão em Desenvolvimento Sustentável - GIIPEDES pelo apoia à pesquisa.

\section{Referências}

Abramovay, R. (1998). Agricultura familiar e serviço público: novos desafios para a extensão rural. Cadernos de Ciência e Tecnologia, 15(1), $132-152$. Atlas do Desenvolvimento Humano no Brasil. (2020). http:// http://www.atlasbrasil.org.br/consulta/map

Baiardi, A. (2014). Gênese e evolução da agricultura familiar: desafios na realidade brasileira e as particularidades do semiárido. Revista Econômica do Nordeste, 45, suplemento especial, 143-156.

Beste, A. (2021). Genau hinsehen lohnt sich. Ein Artikel zu Ökolandbau, Agrarökologie, regenerativer Landwirtschaft und Hybridlandwirtschaft. In: Magazin des Bodenfruchtbarkeitsfonds der Bio-Stiftung, Schweiz.

Brancher, P.C. (2004). As faces da certificação de produtos orgânicos no Brasil: O caso do mercado da Região Metropolitana de Curitiba - PR. In: Congresso da sociedade brasileira de economia, administração e sociologia rural, 42, Cuiabá - MT. Anais.

Campanhola, C. \& Valarini, P. J. (2001). A agricultura orgânica e seu potencial para o pequeno agricultor. Cadernos de Ciência \& Tecnologia, 18(3), 69-101.

Centro de Apoio e Promoção da Agroecologia - Capa. (2021). Atuação. http://www.capa. org.br/page/ atuacao-marechal-c-rondon/

Cardoso, A. G. (2009). A regulação dos produtos orgânicos. Informativo Justen, Pereira, Oliveira e Talamini, 24.

Carlett, A.R. et al. (2019). Importância da certificação de produtos orgânicos pelo programa Paraná Mais Orgânico no oeste e sudoeste do Paraná, sob a perspectiva de agricultores. 14(1). In: 3o Congresso Paranaense de Agroecologia. Foz do Iguaçu/PR. Anais.

Castro, C. N. D., \& Pereira, C. N. (2017). Agricultura familiar, assistência técnica e extensão rural e a política nacional de ATER. Texto para Discussão (TD) 2343. $41 \mathrm{p}$. 
Research, Society and Development, v. 10, n. 14, e405101422071, 2021

(CC BY 4.0) | ISSN 2525-3409 | DOI: http://dx.doi.org/10.33448/rsd-v10i14.22071

Clark, S., Khoshnevisan, B. \& Sefeedpari, P. (2016). Energy efficiency and greenhouse gas emissions during transition to organic and reduced-input practices: Student farm case study. Ecological Engineering, 88, 186-194.

Coelho, C. N. (2001). A expansão e o potencial do mercado mundial de produtos orgânicos. Revista de Política Agrícola, 10(2), 9-26.

Colognese, S. A., Gregory, V. \& Schallenberger, E. (1999). Tupãssi: do mito à história. Cascavel: Edunioeste.

Colognese, S. A. \& Stoffel, J. A. (2007). Organização produtiva da agricultura familiar no Oeste do Paraná. In: Vanderlinde, T.; Gregory, V.; Deitos, N. J. (Orgs.). Século XXI em perspectiva. Cascavel: Coluna do Saber, 69-84.

Corbari, F. (2020). Transição Agroecológica: um estudo de experiências no Brasil e no México. Tese (Doutorado em Desenvolvimento Rural Sustentável) Universidade Estadual do Oeste do Paraná, Marechal Cândido Rondon.

Ecovida. (2004). Caderno de formação: certificação participativa de produtos ecológicos. Florianópolis: Rede Ecovida de Agroecologia, 48 p.

Ehlers, E. (1996). Agricultura sustentável: origens e perspectivas de um novo paradigma. São Paulo: Livros da Terra, 178p.

Engelmann, M. I. (2015). Análise de impacto da certificação orgânica desde uma perspectiva socioeconômica: caso agricultores familiares da rede ecovida de Foz do Iguaçu, Paraná.

Fausto, B. (2013). História do Brasil. São Paulo: EDUSP.

Fonseca. M. F. (2005). A institucionalização dos mercados de orgânicos no mundo e no Brasil: uma interpretação. Tese (Doutorado em Sociologia) Universidade Federal Rural do Rio de Janeiro. Seropédica.

Garcia, J. R. N. (2016). O programa nacional de alimentação escolar como promotor do desenvolvimento rural sustentável e da segurança alimentar e nutricional em Marechal Cândido Rondon - PR. 108 f. Dissertação (Mestrado em Desenvolvimento Rural Sustentável) - Universidade Estadual do Oeste do Paraná, Marechal Cândido Rondon.

Gil, A. (2007). Como elaborar projetos de pesquisa. Atlas: São Paulo.

Gregory, V. (2002). Os eurobrasileiros e o espaço colonial: migrações no Oeste do Paraná (1940 a 1970). Cascavel: Edunioeste.

Grisa, C. \& Schneider, S. (2015). Três gerações de políticas públicas para a agricultura familiar e formas de interação entre sociedade e Estado no Brasil. In: Grisa, C. \& Schneider, S. (Org.). Políticas públicas de desenvolvimento rural no Brasil. Porto Alegre: Editora da UFRGS.

Hoffmann, R. \& Gomes N., M. (2004). Desigualdade, escolaridade e rendimentos na agricultura, indústria e serviços, de 1992 a 2002. Economia e Sociedade, Campinas, 13(2), 23.

Instituto Brasileiro de Geografia e Estatística. (2006). Censo agropecuário 2006. https://sidra.ibge.gov.br/tabela/1111

Instituto Brasileiro de Geografia e Estatística. (2010). Censo IBGE 2010. https://censo2010.ibge.gov.br/

Instituto Brasileiro de Geografia e Estatística. (2017). Censo agropecuário 2017. https://censos.ibge.gov.br/agro/2017

Instituto Brasileiro de Geografia e Estatística. (2018). Produção da extração vegetal e da Silvicultura 2018.

https://sidra.ibge.gov.br/pesquisa/pevs/quadros/brasil/2018

Instituto Brasileiro de Geografia e Estatística. (2019). Agência IBGE Notícia. https://agenciadenoticias.ibge.gov.br/agencia-noticias/2012-agencia-denoticias/noticias/25126-em-alta-agricultura-organica-reune-todos-os-elementos-da-producao-sustentavel.

International Federation of Organic Agriculture Movements. (2008). Sistemas Participativos de Garantía: Estudios de caso de: India, Nueva Zelandia, Brasil, Estados Unidos, Francia. Alemanha: IFOAM. http://www.ifoam.org/

Instituto Paranaense de Desenvolvimento Econômico Social. (2017). Caderno estatístico do município de Marechal Cândido Rondon - PR. http://www.ipardes.gov.br/cadernos

Instituto de Pesquisa Econômica Aplicada. (2012). Fiscais da saúde dos alimentos - Empresa de Botucatu é exemplo de certificadora de produtos orgânicos. http://desafios.ipea.gov.br/index.php?option=com_content\&view=article\&id=1 417:catid=28\&Itemid=23

Leal, L. S. G., Pizzaia, L. G. E. \& Ferrante, V. L. S. B. (2018). As mulheres na produção orgânica na região de Araraquara: rompendo invisibilidades. In: Simpósio sobre Reforma Agrária e Questões Rurais. Araraquara/SP. Anais.

Leonel, A. P. S. et al. (2011). Dinâmica de funcionamento da agricultura orgânica no Município de Marechal Cândido Rondon - PR. Revista Cultivando o saber. Cascavel, 4(4), 129-143.

Lima, R.S. \& Fontana, A. P. C. (2019). As feiras da agricultura familiar como território de práticas alimentares e sociabilidades. Revista do Desenvolvimento Regional, 24(3), 75-100.

Lima, S. K., Galiza, M., Valadares A., Alves, F. (2020). Produção e Consumo de Produtos Orgânicos no Mundo e no BrasilTexto para discussão. Instituto de Pesquisa Econômica Aplicada. Brasília: Rio de Janeiro: Ipea.

Magalhães, V. L. \& Cunha, J. E. da. (2006). O solo como base da sustentabilidade agrícola: estudo de caso no município de Marechal Cândido Rondon-PR. Raega - O Espaço Geográfico em Análise, [S.1.], 12. ISSN 2177-2738. https://revistas.ufpr.br/raega/article/view/4496 
Research, Society and Development, v. 10, n. 14, e405101422071, 2021

(CC BY 4.0) | ISSN 2525-3409 | DOI: http://dx.doi.org/10.33448/rsd-v10i14.22071

Marechal Cândido Rondon. (2018). Decreto $N^{o}$ 339, de 30 de Outubro de 2018. https://leismunicipais.com.br/a/pr/m/marechal-candidorondon/decreto/2018/34/339/decreto-n-339-2018-regulamenta-a-lei-n-4904-que-dispoe-sobre-a-obrigatoriedade-de-aquisicao-de-alimentos-organicos-ou-de-base agroecologica-na-alimentacao-escolar-no-ambito-do-sistema-municipal-de-ensino-de-marechal-candido-rondon-e-da-outras-providencias

Miklós, A. A. de W. (2019). Agricultura biodinâmica, nutrição e desenvolvimento humano. São Paulo: Associação Brasileira de Agricultura Biodinâmica, 5.172KB; PDF. https://biodinamica.org.br/images/ebook_nutricao_baixa.pdf

Ministério da Agricultura, Pecuária e Abastecimento. (2019). Regularização da produção orgânica http://www.agricultura.gov.br/desenvolvimentosustentavel/organicos/regularizacao-producao-organica

Ministério da Agricultura, Pecuária e Abastecimento. (2020). Cadastro nacional de agricultores orgânicos. https://www.gov.br/agricultura/ptbr/assuntos/sustentabilidade/organicos/cadastro-nacional-produtores-organicos

Miollo, J.R. (2019). Agroecologia ou agricultura orgânica: reflexões a partir dos processos de certificação na agricultura familiar. 191 f. Dissertação (Mestrado em Extensão rural) - Universidade Estadual de Santa Maria, Santa Maria/RS

Moraes, M. D. \& Oliveira, N. A. M. (2017). Produção orgânica e agricultura familiar: obstáculos e oportunidades. Desenvolvimento Socioeconômico em Debate, 3(1), 19-37.

Moresco, M.D. (2007). Estudos de paisagem no município de Marechal Cândido Rondon - PR. 2141 f. Dissertação (Mestrado em Geografia) - Universidade Estadual de Maringá, Maringá/PR.

Navolar, T. S., Rigon, S. A. \& Philippi, J. M. S. (2010). Diálogo entre agroecologia e promoção da saúde. Revista Brasileira em Promoção da Saúde, 23(1), 6979.

Oliveira, E. R. \& Ribeiro, E. M. (2002). Indústria rural, agricultura familiar e desenvolvimento local: o caso da produção de cachaça artesanal em Salinas-Minas Gerais. In: Seminário sobre a Economia Mineira. Diamantina, MG. Anais.

Organis. (2019). Panorama do consumo de orgânicos no Brasil em 2019. https://organis.org.br/pesquisa-consumidor-organico-2019/

Ormond, J. G. P. (Org.). (2002). Agricultura orgânica: quando o passado é futuro. BNDES Setorial, Rio de Janeiro, 15, 3-34.

Paula, A., Jr. (2019). Escolaridade nas zonas rurais da região sul. Espaço e Economia, 16.

Polanyi, K. (2000). A grande transformação: as origens de nossa época. Tradução de Fanny Wrabel. - 2. ed.- Ria de Janeiro: Compus, 337 p.

Reganold, J. \& Wachter, J. (2016). Organic agriculture in the twenty-first century. Nature Plants 2, 15221. https://doi.org/10.1038/nplants.2015.221

Ribeiro, C. (2020). Mulheres do campo e práticas de cuidado: contribuições para o debate sobre agroecologia e saúde. Cadernos de Agroecologia, 15. 3 ed.

Rosset, P. \& Altieri, M. (2019). Agroecología: Ciencia y política. Ciudad de México: Miguel Angel Porrúa.

Schindecker, S. M. (2015). Die Entwicklung der biologischen Landwirtschaft in Salzburg - Rückblick und Ausblick. Masterarbeit, Betreuerinnen: Assoc. Prof. Dr. Ika Darnhofer DI Agnes Strauss. Institut für Agrar- und Forstökonomie, Department für Wirtschafts- und Sozialwissenschaften, Universität für Bodenkultur Wien, Wien.

Seyferth, G. (1974). A colonização alemã no Vale do Itajaí-Mirim. Porto Alegre: Movimento.

Siliprandi, E. (2015). Mulheres e agroecologia: transformando o campo, as florestas e as pessoas. Rio de Janeiro: Editora UFRJ.

Signor, A. A., Zibetti, A. P. \& Feiden, A. (2011). Produção orgânica animal. Toledo: GFM.

Stoffel, J. A. (2004). A viabilidade da agricultura familiar: formas de organização produtiva no Oeste do Paraná. Dissertação (Mestrado em Desenvolvimento Regional e Agronegócio) - Universidade Estadual do Oeste do Paraná, Toledo.

Til, A. M., Rosa, G. R. \& Santos, L. H. (2020). Mulheres e Agroecologia: diálogos de re-existência no Sul do Sul. Cadernos de Agroecologia, 15. 3 ed.

Tomasetto, M. Z. C., Lima, J. F. \& Shikida, P. F. A. (2009). Desenvolvimento local e agricultura familiar: o caso da produção de açúcar mascavo em Capanema Paraná. INTERAÇÕES, Campo Grande, 10(1), 21-30.

Troiano, J. A. (2015). A subjetividade do novo agente produtivo-consumidor na produção orgânica: algumas experiências brasileiras e espanholas. 1 CD-ROM. Trabalho de conclusão de curso (bacharela - Ciências Sociais) - Universidade Estadual Paulista Julio de Mesquita Filho. Araraquara/SP.

Veiga, J. E. (1996). Agricultura familiar e sustentabilidade. Cadernos de Ciência e Tecnologia. Brasília, DF, 13(3), 383-404.

Vergutz, C. L. B. \& Bernado, M. (2020). Mulheres, alimentação e agroecologia. Cadernos de Agroecologia, 15. 3 ed.

Veronezi, F. \& Bastos, T. L. (2012). Agricultura familiar orgânica: alternativa de permanência no campo para o pequeno produtor da região centro-sul do estado do Paraná. XXI Encontro Nacional de Geografia Agrária. Uberlândia - MG. Anais. http://www.lagea.ig.ufu.br/xx1enga/ anais_enga_2012/eixos/1130_2.pdf

Vicente, J. R., Anefalos, L.C. \& Caser, D.V. (2003). Influência de capital humano, insumos modernos e recursos naturais na produtividade agrícola. Região e espaço no desenvolvimento agrícola brasileiro. Rio de janeiro: Ipea, 265-295.

Webster, J. \& Watson, J.T. (2002). Analyzing the past to prepare for the future: writing a literature review. MIS Quarterly \&The Society for Information Management, 26(2), 13-23. 